\title{
Do people really care about global warming?
}

\author{
Francesco Busato • Bruno Chiarini • Gianluigi Cisco* • Maria Ferrara
}

University of Naples Parthenope, Italy

Received: 11 January 2021

Revised: 24 July 2021

Accepted: 9 September 2021

\begin{abstract}
Global warming represents a "hot" topic in our current daily life. This paper builds up and simulates a dynamic stochastic general equilibrium (DSGE) model in the spirit of Nordhaus (2008) while investigating consumers' behavior in a context where economic and environmental issues interact. The paper suggests that households do not care about global warming as much as they should. Even if households make pro-environmental consumption choices, their investment decisions focus on the economic aspect mainly. Therefore, households' propensity to consume clean products is not sufficient to produce benefits to the environment.
\end{abstract}

Keywords: Green preferences; Environmental awareness; Global warming; Consumers behavior; Dynamic stochastic general equilibrium

JEL Classification Codes: E32, Q51, Q54

\section{Introduction}

Household behavior is a crucial component in climate policies since individuals can save immense amounts of carbon ("behavioral mitigation wedge") simply by changing their diet to avoid meat or forgoing air travel. Faber et al. (2012) find that behavioral change contributes to removing between $4 \%$ and $8 \%$ of the overall $\mathrm{CO}_{2}$ emissions.

The international climate policy debate has been fixated on technology and economic incentives and has often relegated behavioral change to an afterthought, rather than having it join the center stage (Dubois et al. 2019). While contributions focusing on the supply side of the economy in a Dynamic Stochastic General Equilibrium (DGSE) framework are numerous (e.g., Fisher and Springborn, 2011; Heutel, 2012), studies investigating the consumers' behavior are scant.

This paper is a first attempt to fill this gap being a part of this field of literature. An approach to household green preferences in a DSGE context is particularly welcome for several reasons. First, the households' pro-environment behavior is time-varying and pro-cyclical (Scruggs and Benegal, 2012). Second, the demand side of the economy does matter because consumers incentivize producers to supply environmentally careful products. Given the discussion above,

\footnotetext{
*Corresponding author. E-mail: gianluigi.cisco@uniparthenope.it.
}

Citation: Busato, F., Chiarini, B., Cisco, G., and Ferrara, M. (2022) Do people really care about global warming?, Economics and Business Letters, 11(1), 24-32.

DOI: $10.17811 / \mathrm{ebl} \cdot 11.1 .2022 .24-32$ 
there is a clear need to dig into the fundamental issues of household decision-making processes and their impact on macroeconomic variables.

Here comes the contribution of this paper. It asks: (i) Do people really care about global warming? (ii) what is the role of green preferences in achieving emissions reduction?

This paper presents a DSGE model where consumers may choose between "clean" (low-carbon technology) and "dirty" (environmental polluting) goods. In this context, consumer behavior is affected by environmental quality, modeled as an externality.

The answer to the first question suggests that people do not care about global warming as much as they should. Our model explains that after productivity shocks there is an income effect prevailing on environmental concerns. The answer to the second question is linked to the first one. Green preferences play only a marginal role in affecting household behavior. In fact, although households are more incentivized to consume cleaner goods after a preference shock, in a forward-looking perspective the economic issue always takes over the environmental one. This suggests that a cultural change, an environmental awareness that develops and evolves over time, rather than in one shot, is necessary to reduce emissions and global warming. This is our innovative message.

This manuscript contributes to existing literature augmenting Heutel (2012) and Angelopoulos et al. (2013) by adding green and dirty firms and allowing households to change preferences about green products through a preference shock. In addition, while Acemoglu et al. (2012) consider a unique final good produced by combining the inputs in a two-sector model, we assume two final goods, namely, clean and dirty.

The remainder of the paper is organized as follows. We present the basic framework in Section 2. Section 3 comments on our results. Section 4 provides concluding remarks and future research agenda.

\section{A DSGE model of the climate change}

This section sketches fundamentals of the economy, leaving aside the equilibrium characterization of the model and focusing on the economic and environmental insights ${ }^{1}$. The economy is modeled as a two-sector DSGE model where the environmental side of the economy is designed à la Nordhaus (2008). The economy is populated by homogenous households, and final good producers operating in two different sectors: a " clean sector" using a clean technology that does not generate toxic emissions, and a "dirty sector" employing a polluting technology ${ }^{2}$. Emissions, next, affect the environment and consumer behaviors.

\subsection{Preferences}

Representative household maximizes its expected utility function defined over consumption index $C_{t}$ (defined below) and environmental quality $Q_{t}$ (considered as given) and disutility from hours worked in the dirty sector $\left(L_{D, t}\right)$ and in the clean one $\left(L_{C, t}\right)$ :

$$
U_{t}\left(C_{t}, Q_{t}, L_{c, t}, L_{d, t}\right)=E_{t} \sum_{t=0}^{\infty} \beta^{t}\left[\frac{\left(C_{t}^{\mu} Q_{t}^{(1-\mu)}\right)^{(1-q)}}{(1-q)}-\theta_{c} \frac{L_{c, t}^{1+\psi_{c}}}{1+\psi_{c}}-\theta_{d} \frac{L_{d, t}^{1+\psi_{d}}}{1+\psi_{d}}\right]
$$

where $E_{t}$ is the expectation operator, $\beta \in(0,1)$ is the subjective discount factor, q denotes a risk aversion parameter and $\mu \in(0,1)$ represents the weight assigned to consumption in the utility function, $\theta_{c}$ and $\theta_{d}$ are the disutility parameter from clean and dirty labor, $\psi_{d}$ and $\psi_{c}$ are the Frish elasticity parameters. The idea is that consumers are happier, in the sense that obtain

\footnotetext{
${ }^{1}$ Model details are available upon request.

${ }^{2}$ Besides this simplifying assumption, we could take into account that also the clean sector might emit, even if to a lesser extent than in the dirty sector. This is in our ongoing research agenda.
} 
more utility from their consumption profile when living in a greener and healthier environment (i.e. when Q is "high"). To keep the model simple, the paper assumes no disutility from labor; hence consumers are expected to inelastically supply their labor services. Households consumption basket $C_{t}$ is described by a constant elasticity of substitution (CES) aggregate consumption bundle defined over the two sectors, clean (c) and dirty (d) respectively:

$$
C_{t}=\left(\gamma_{t}^{1 / \varepsilon} C_{c, t}^{((\varepsilon-1) / \varepsilon)}+\left(1-\gamma_{t}\right)^{1 / \varepsilon} C_{d, t}^{((\varepsilon-1) / \varepsilon)}\right)^{(\varepsilon /(\varepsilon-1))},
$$

where $\varepsilon$ is the constant elasticity of substitution parameter and $\gamma_{t} \in(0,1)$ measures households pro-environmental consumption. According to Joshi and Rahman (2015), environmental awareness is time-varying and is closely related to $\mathrm{CO} 2$ emissions. Besides, the model presents a shock that affects public opinion about the environmental issue:

$$
\gamma_{t}=\bar{\gamma} V_{t}
$$

where $\bar{\gamma}$ is the initial value of the clean consumption preferences and $V_{t}$ is preference shock. This shock is considered as an event that makes consumers more sensitive to environmental issues. The representative households maximize the utility function subject to the following inter-temporal budget constraint:

$$
P_{d, t} C_{d, t}+P_{c, t} C_{c, t}+P_{d, t} I_{d, t}+P_{c, t} I_{c, t}=W_{d, t} L_{d, t}+W_{c, t} L_{c, t}+R_{d, t} K_{d, t-1}+R_{c, t} K_{c, t-1},
$$

where $W_{j, t} L_{j, t}$ denotes labor income and $R_{j, t} K_{j, t-1}$ is the rental income from capital services ${ }^{3}$. In each period t representative household makes consumption and investment decisions taking into account of her income.

\subsection{Production technologies}

The clean good is produced by means of a Cobb-Douglas production function:

$$
Y_{t}^{c}=A_{t}^{c}\left(K_{t}^{c}\right)^{\alpha_{c}}\left(L_{t}^{c}\right)^{\left(1-\alpha_{c}\right)},
$$

where $K_{t}^{c}$ and $L_{t}^{c}$ respectively denote the clean capital and labor inputs, $A_{t}^{c}$ is an exogenous sectoral process of total factor productivity (TFP) in the clean sector, and $\alpha_{c}$ is the sectoral share of the clean capital. As labor, capital is sector specific, in the sense that once in place capital stock cannot be disinvested, but it can only depreciate over time. This paper makes the simplifying assumption stating that clean goods are produced with a clean technology, and dirty goods with a dirty technology.

Dirty good is produced with a Cobb - Douglas technology as well:

$$
Y_{t}^{d}=A_{t}^{d}\left(K_{t}^{d}\right)^{\alpha_{d}}\left(L_{t}^{d}\right)^{\left(1-\alpha_{d}\right)},
$$

where $K_{t}^{d}$ and $L_{t}^{d}$ respectively represent dirty capital and labor, $A_{t}^{d}$ denotes an exogenous sectoral process of total factor productivity in the dirty sector, and $\alpha_{d}$ is the sectoral share of the dirty capital.

\subsection{The environmental side of the model}

Environment is modeled in the spirit of Nordhaus (1993, 2008) emissions equation (Eq. 7) linking $\mathrm{CO}_{2 t}$ emissions to the dirty output via the parameter $\xi$ denoting the emission per unit of dirty output.

$$
C O_{2 t}=\xi Y_{D, t}
$$

\footnotetext{
${ }^{3}$ where $\mathrm{j}=\mathrm{c}, \mathrm{d}$
} 
This is an important transmission channel through which environmental issue and the economic concern interact. The emission stock $M_{t}$ evolves according to:

$$
M_{t}=\left(1-\delta_{m}\right) M_{t-1}+C O_{2 t},
$$

where $\delta_{m}$ denotes a natural depreciation rate. In addition, $M_{t}$ defines the radiative forcing in the atmosphere:

$$
F_{t}=\eta\left[\ln \left(\frac{\left(M_{t}\right) / \bar{M}}{2}\right)\right],
$$

where $\bar{M}$ represents the pre-industrial carbon emissions concentration and $\eta$ denotes the forcing parameter. When the levels of atmospheric carbon exceed the pre-industrial level, the radiative forcing grows up and temperature $\left(T_{t}\right)$ increases as follows:

$$
T_{t}=\lambda^{1} T_{t-1}+\lambda^{2} F_{t}
$$

in which $\lambda^{1} \in(0,1)$ capture the persistence deviations in surface temperature and $\lambda^{2}$ is the weight of radiative forcing on global temperature deviation. The environmental quality is treated as an accumulation process, as in Jouvet et al. (2005), and evolves according to:

$$
Q_{t}=f\left(Q_{t-1}\right)-T_{t}
$$

with $0<f^{\prime}\left(Q_{t-1}\right)<1$ and $f^{\prime \prime}\left(Q_{t-1}\right) \leq 0$. The environmental quality steady-state is at its maximum when global warming does not appear.

\section{Calibration}

In this section, we summarize the parametrization of the model, which is in line with the existing literature. The model is calibrated for the United States economy, being a good example for a developed economy, and time is in quarters. Parameters characterizing the dirty economy and household preferences are standard in literature on general equilibrium modeling (see, e.g., King and Rebelo, 1999). Parameters defining the environmental sector align with Nordhaus (2008) and Angelopoulos et al. (2013).

Table 1. Model calibration.

\begin{tabular}{clrl}
\hline \hline Parameter & Description & Value & Source \\
\hline $\boldsymbol{q}$ & Risk aversion parameter & 2 & King and Rebelo (1999) \\
$\boldsymbol{\mu}$ & Consumption weight & 0.6 & Angelopoulos et al. (2013) \\
$\boldsymbol{\psi}_{\boldsymbol{c}}$ & Frish Elasticity- clean & 1 & King and Rebelo (1999) \\
$\boldsymbol{\psi}_{\boldsymbol{d}}$ & Frish Elasticity- dirty & 1 & King and Rebelo (1999) \\
$\boldsymbol{\varepsilon}$ & Elasticity of substitution & 1.5 & Acemoglu (2012) \\
$\overline{\boldsymbol{\gamma}}$ & Clean Consumption Preference & 0.4 & Gallup Data \\
$\boldsymbol{\beta}$ & Discount Factor & 0.975 & King and Rebelo (1999) \\
$\boldsymbol{\alpha}_{\boldsymbol{c}}$ & Clean Capital Share & 0.36 & Argentiero et al. (2017) \\
$\boldsymbol{\alpha}_{\boldsymbol{d}}$ & Dirty Capital share & 0.39 & Argentiero et al. (2017) \\
$\boldsymbol{\delta}_{\boldsymbol{c}}$ & Depreciation Rate Clean & 0.05 & Endogenous Calibration \\
$\boldsymbol{\delta}_{\boldsymbol{d}}$ & Depreciation Rate Clean & 0.025 & King and Rebelo (1999) \\
$\boldsymbol{\xi}$ & Emission per unit of dirty output & 0.45 & Heutel (2012) \\
$\boldsymbol{\delta}_{\boldsymbol{m}}$ & Natural depreciation rate & 0.002 & Nordhaus (2008) \\
$\boldsymbol{\eta}$ & Forcing Parameter & 3.8 & Nordhaus (2008) \\
$\boldsymbol{\lambda}^{\mathbf{1}}$ & Persistence deviations in surface temperature & 0.90 & Nordhaus (2008) \\
$\boldsymbol{\lambda}^{\mathbf{2}}$ & Forcing weight & 0.15 & Nordhaus (2008) \\
\hline \hline
\end{tabular}


The clean consumption preferences are set considering the Gallup Organization survey $(\bar{\gamma}=$ 0.4). In order to calibrate clean technology, this study follows Argentiero et al. (2017). This latter reports a larger capital share in the dirty sector than the clean one $\left(\alpha_{c}=0.36\right.$ and $\left.\alpha_{d}=0.39\right)$. The depreciation rate for the clean capital is set to capture the actual ratio between green and dirty investments $\left(\delta_{\mathrm{c}}=0.05\right)$.

\section{Results}

This section offers a first glance at the model's capabilities and discusses impulse response functions (IRFs). We simulate the case of a positive productivity shock in both dirty and clean sectors ${ }^{4}$ and a demand shock, namely a preference shock in the clean sector, to investigate the consumers' willingness to consume clean goods ${ }^{5}$.

\subsection{Environmental insights vs economic insights: The economic mechanisms}

Simulating technology shocks provides insights to answer our research question: Do people really care about global warming? Moreover, they allow understanding the economic mechanisms behind their consumption and investment choices.

Figure 1 shows the responses of the environmental and selected economic variables to the two supply shocks. After a $1 \%$ positive productivity shock in the dirty sector, emissions increase on impact (see Eq. 7) while the temperature reacts only during the propagation of the shock, given the backward looking nature of equations 8 and 10. The increase in $\mathrm{CO}_{2}$ concentration affects the temperature path via Eq. 8 and Eq. 9, entailing a negative externality; i.e. the environmental quality $Q_{t}$ decreases because of the temperature increase (Eq. 11). In our rational expectation model, households discount that temperature is rising in the future and therefore increase clean consumption because of their environmental awareness. Hence, both dirty and clean consumption rise, although different reasons. The dirty consumption increases for the income effect and clean consumption increases because households are also sensitive to environmental concerns. However dirty consumption increases more than clean consumption: global warming is not seriously considered. In addition, households prefer to invest in the dirty sector disinvesting in the clean one; consequently, the clean aggregate demand falls down. Only consumption choices are affected by environmental awareness, whereas investments follow an economic logic. Hence, after a dirty technology shock, dirty investment is increasingly attractive, whereas green investment is becoming less profitable. Finally, the rise in clean consumption is not sufficient to avoid a recession in the clean sector.

Following a positive productivity shock in the clean sector, emissions and temperature decrease. Households reallocate their resources from dirty to clean capital pushing down production in the dirty sector, affecting therefore environmental variables via Eq. 7. Importantly, the size of the effects of the two supply shocks is considerably different. While emissions increase by $1.5 \%$ after the "dirty" shock their reduction is rather tiny after the "clean" shock. This explains why after the "dirty" shock the temperature increase is persistent, whereas after the "clean" shock temperature falls down on impact and then increases. Consequently, while after the "dirty" shock the increase in the clean consumption is persistent and features the standard hump-shaped dynamics, after the "clean" shock dirty consumption increases on impact and increases more than the clean one. Also, in this case, consumers do not care enough about global warming since they discount that temperature is lowering and increase the cheaper dirty good. Under these hypotheses, earth temperature does not significantly impact consumers' behavior.

\footnotetext{
${ }^{4}$ For example, technical innovation in fossil fuel extraction and technical advances in green technologies (solar, hydro, and wind), respectively.

${ }^{5}$ The simulations have been obtained using numerical analysis and perturbation methods to simulate the economy and compute the equilibrium conditions outside the steady state. We solve the model using a second-order Taylor approximation around its steady state.
} 
Figure 1. Economic Insights vs Environmental Insights.
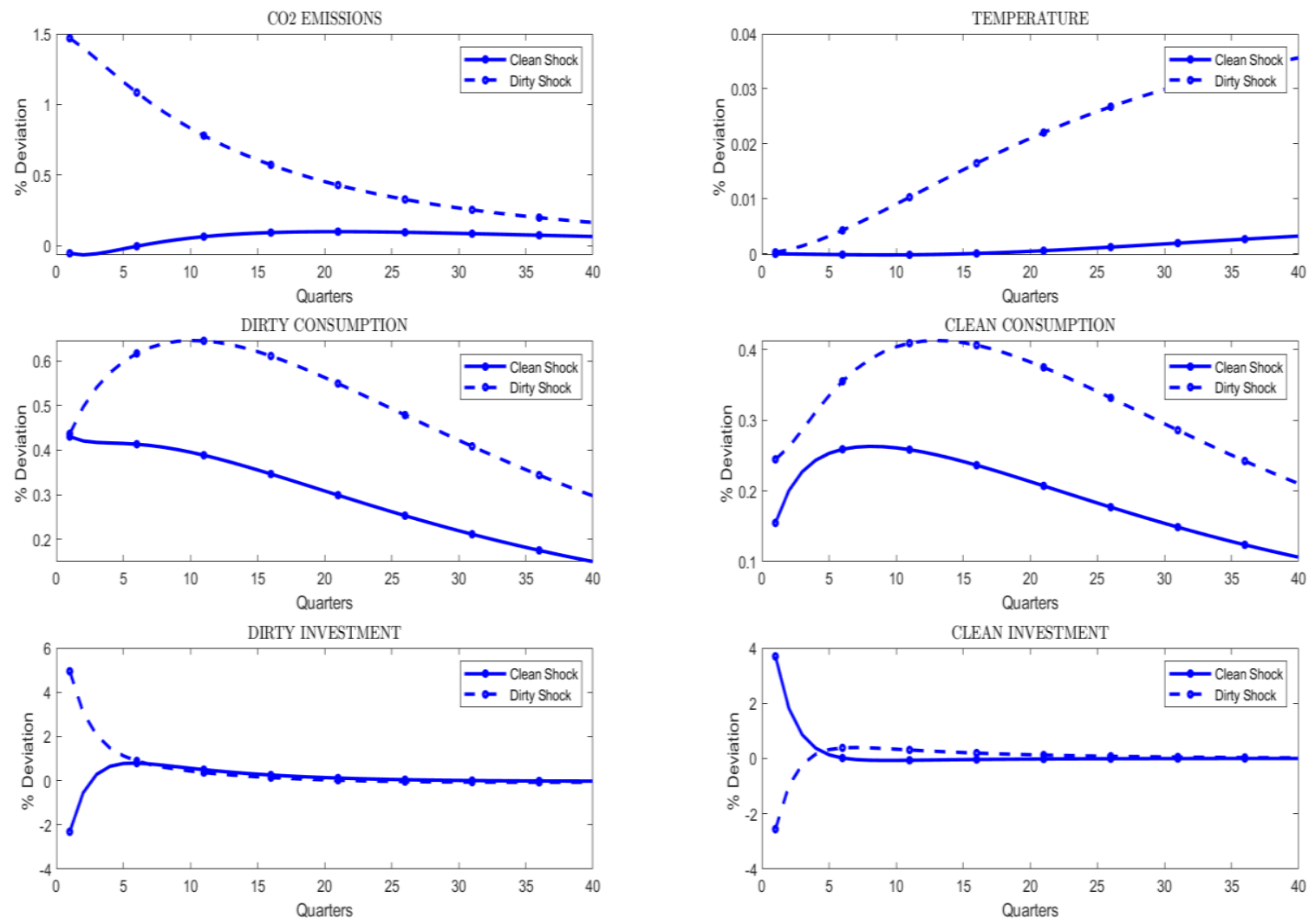

\subsection{Demand - Preference Shock}

In this section, we simulate a preference shock to investigate the role of green preferences in achieving emissions reduction (Figure 2).

The preference shock can be seen as a change in consumer preferences in the sense that they become more sensitive to environmental problems. A Greta Thunberg speech, a national campaign toward the environment, or extreme weather events influencing the households' environmental concern, can be seen as a preference shock of this kind. If consumers become more sensitive to the environmental issue, clean consumption rises, determining a reduction in dirty relative prices. This makes it convenient to disinvest in the clean sector and invest in the dirty sector. Therefore, the clean demand features a sharp and long recession caused by a sizable drop in investment. By the opposite, the rise in dirty investments drives the growth in the polluting sector. Consequently, emissions raise and lead to an increase in temperature throughout the propagation of the shock. Therefore a preference shock stimulates the propensity of families to consume clean goods, but it is not enough to overcome the problem of global warming.

\subsection{Correlated shocks}

In the previous analysis, we assume independence between dirty and clean productivity shocks. In this section we consider a positive correlation between sectoral TFP shocks. More precisely, we examine the case in which a standard dirty technology shock also affects productivity in the clean sector. To this end, Figure 3 shows the IRFs for environmental variables, sectoral consumption, and investments after a correlated technology shock, compared to a non-correlated dirty TFP shock.

The correlation between the two shocks mainly affects sectoral productivity. Consequently, part of households' resources invested in the dirty sector is transferred to the clean one, which benefits from the spillover dirty technology effect. This latter allows improving the production process in the clean sector. As a result, consumption in both sectors increases more than in the baseline scenario. As a consequence, correlated shocks increase $\mathrm{CO} 2$ emissions in the long run. 
Figure 2. Preference Shock.
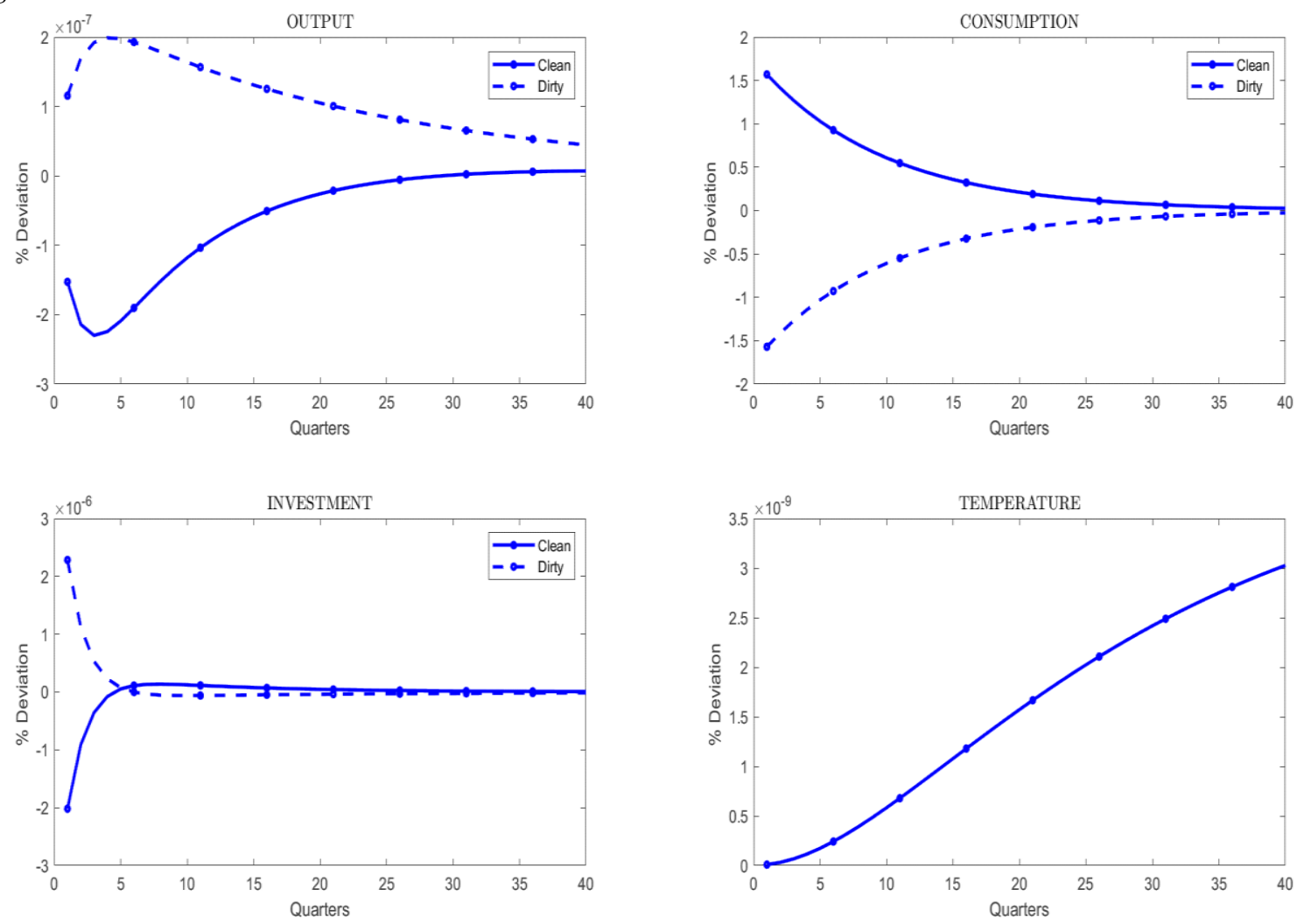

Figure 3. IFRs after a dirty technology shock correlated to green technology.
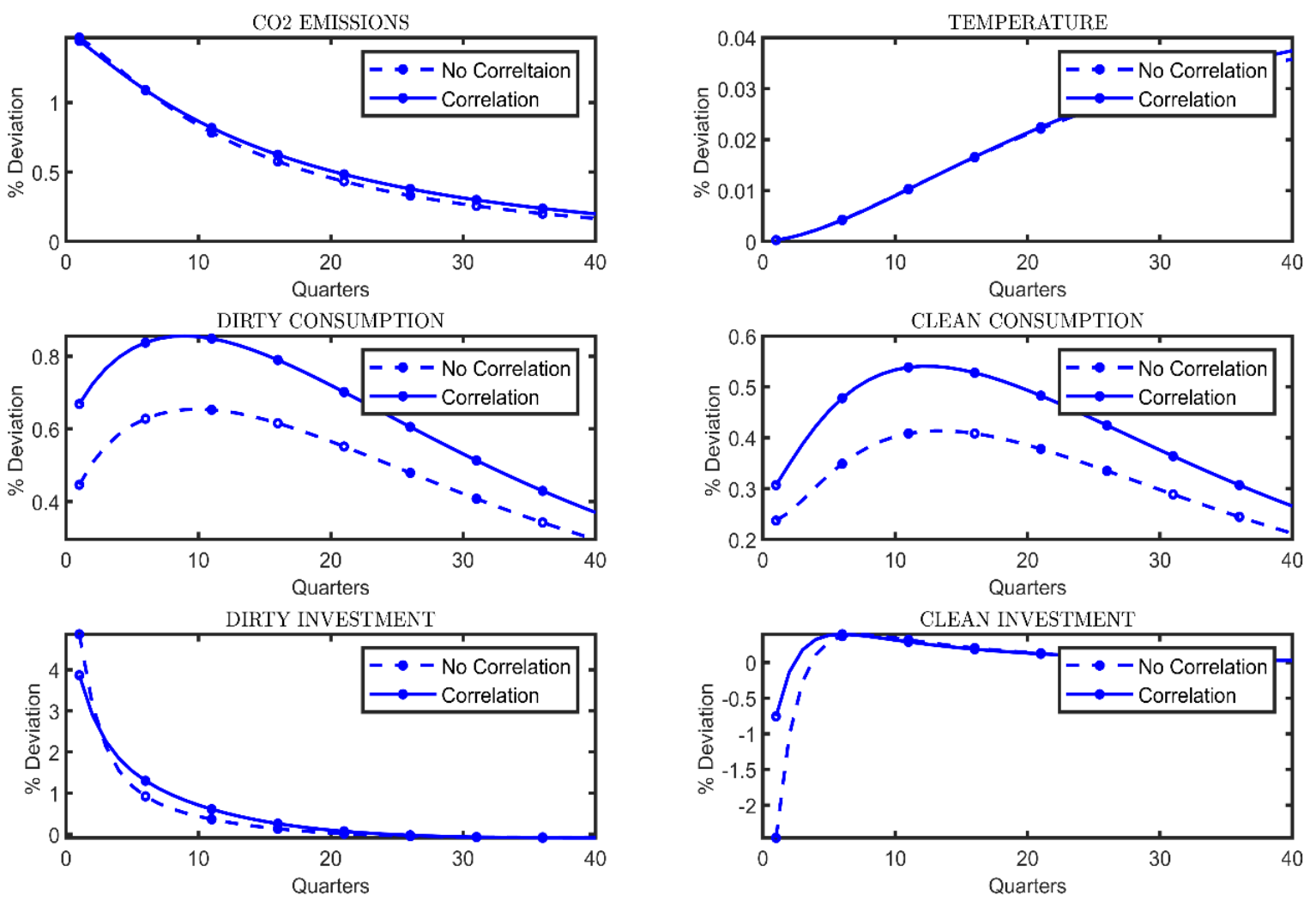


\section{Conclusions}

This letter provides selected insights to reason on how people care about global warming, while choosing between clean and dirty goods and deciding how to allocate their saving between clean and dirty investments. To investigate this question (and possibly many others), the paper designs an equilibrium model capable to capture the trade-off between environmental - compliant choices and those based only on crude economic drivers. Impact over temperature and global warming is modeled in the spirit of Nordhaus contributions.

This study suggests that consumers' choices are still very much tied to relative prices: consumers, even being aware that climate change is an ongoing important issue, still have incentive to consume (and indeed consume) the cheaper commodities, which are, in fact, the relatively more polluting. The mechanism is reinforced when the relatively more polluting sector becomes more efficient, following a technological improvement. These behaviors push up earth temperature. On the other hand, green preferences play only a marginal role in affecting households' behavior. In fact, a Greta Thunberg speech (that technically could be modeled as a temporary preference shock) stimulates the consumption of clean goods but this is not sufficient to overcome the global warming issue of course. In fact, even after a preference shock the economic concern prevails on the environmental one pushing down clean investments and up the dirty ones.

Our message is clear: controlling against global warming requires a structural change in households' preferences. To this purpose, it is necessary that an environmental awareness, internalizing the increase in global warming, develop. Modelling these challenging insights is already in our research agenda, aiming to contribute to the literature along both economic and policy dimensions.

\section{Acknowledgements}

The authors acknowledge for helpful discussions participants to seminar at Warsaw University of Life Sciences, to the 24th EAERE Annual Conference, to the 7th International PhD Meeting at the University of Macedonia.

\section{Authors' declarations}

The authors declare that the manuscript has not been previously published in its current form or a substantially similar form and is not currently under review by another journal.

\section{References}

Acemoglu, D., Aghion, P., Bursztyn, L., \& Hemous, D. (2012). The environment and directed technical change. American Economic Review, 102(1), 131-66.

Angelopoulos, K., Economides, G., \& Philippopoulos, A. (2013). First-and second-best allocations under economic and environmental uncertainty. International Tax and Public Finance, 20(3), 360-380.

Argentiero, A., Atalla, T., Bigerna, S., Micheli, S., \& Polinori, P. (2017). Comparing Renewable Energy Policies in EU-15, US and China: A Bayesian DSGE Model. The Energy Journal, 38 (KAPSARC Special Issue).

Dubois, G., Sovacool, B., Aall, C., Nilsson, M., Barbier, C., Herrmann, A., \& Dorner, F. (2019). It starts at home? Climate policies targeting household consumption and behavioral decisions are key to low-carbon futures. Energy Research \& Social Science, 52, 144-158.

Faber, J., Schroten, A., Bles, M., Sevenster, M., Markowska, A., Smit, M., ... \& Zimmermann, K. (2012). Behavioural climate change mitigation options and their appropriate inclusion in quantitative longer term policy scenarios. Delft: CE Delft. 
Fischer, C.,Springborn,M.,(2011).Emissions targets and the real business cycle:intensity targets versus caps or taxes, Journal of Environmental Economics and Management, 62, 352-366.

Heutel, G., (2012). How should environmental policy respond to business cycles? Optimal policy under persistent productivity shocks. Review of Economic Dynamics, 15, 244-264.

Jouvet, P.A.,Michel, P., \& Rotillon,G., (2005). Optimal growth with pollution: how to use pollution permits?. Journal of Economic Dynamics and Control, 29 (9), 1597-1609.

Nordhaus, W.D. (2008). A Question of Balance: Weighing the Options on Global Warming Policies. Yale University Press, New Haven and London.

Scruggs : Scruggs, L., \& Benegal,S., (2012). Declining public concern about climate change: Can we blame the great recession?. Global Environmental Change, 22 (2), 505-515. 